\title{
Extensão universitária na educação de jovens e adultos no contexto prisional: uma proposta educativa dialógica
}

Maria Lígia Isídio Alves ${ }^{1}$, Jucilene Nascimento Dias² ${ }^{2}$ Severino Bezerra da Silva ${ }^{3}$

\section{Resumo}

O presente texto tem como objetivo apresentar algumas reflexões acerca das perspectivas metodológicas do "Projeto de Extensão Universitária Educação de Jovens e Adultos (EJA) no contexto prisional". Trata-se de um projeto vinculado à Universidade Federal da Paraíba (UFPB), que abrangeu cerca de 80 (oitenta) educadores que atuam nas unidades prisionais do estado. É uma proposta educativa pautada na horizontalidade das decisões e no diálogo como princípio fundante para a organização, sistematização e (re)orientação da condução do processo de construção do conhecimento dos sujeitos envolvidos. Optou-se por problematizar e apresentar essa experiência a partir de autores que discutem educação popular (FREIRE, 1981, 1997, 2011a, 2011b), EJA em prisões (IRELAND, 2011; MAEYER, 2011; MUÑOZ, 2011) e extensão universitária (FREIRE, 1983; MELO NETO, 2012). O percurso metodológico baseia-se numa abordagem qualitativa, com estudo de caso de cunho descritivo. Adotaram-se como procedimentos metodológicos a observação participante e a análise documental (relatório dos encontros), e têm-se como sujeitos da pesquisa, professores e agentes penitenciários da educação de jovens e adultos participantes do mencionado projeto, assim como os professores/pesquisadores. Nessa ação extensionista, consideraram-se os interesses, as necessidades educacionais e humanas dos atores que fazem o cotidiano na prisão.

\section{Palavras-chave}

Educação de Jovens e Adultos em Prisões. Diálogo. Extensão Universitária.

1. Doutoranda em Educação na Universidade Federal da Paraíba; membro do Grupo de Pesquisa Observatório da Educação Popular do Programa de Pós-Graduação em Educação. E-mail: ligia.isidio@gmail.com.

2. Mestre em Educação pela Universidade Federal da Paraíba. E-mail: jucilenedias@hotmail.com.

3. Doutor em Ciências Sociais pela Pontifícia Universidade Católica de São Paulo; professor associado IV da Universidade Federal da Paraíba; membro do Grupo de Pesquisa Observatório da Educação Popular do Programa de Pós-Graduação em Educação. E-mail: severinobsilva@uol.com.br. 


\title{
University extension in education of youth and adults in the prisonal context: a dialogical educational proposal
}

Maria Ligia Isidio Alves", Jucilene Nascimento Dias", Severino Bezerra da Silva***

\begin{abstract}
The present text aims to present some reflections on the methodological perspectives of the "University Extension Project Education of Youth and Adults (EJA)" in the prison context. It is a project linked to the Federal University of Paraíba (UFPB), which included about eighty educators who work in the prison units of the state of Paraíba, Brazil. It is an educational proposal based on the horizontality of decisions and dialogue as a founding principle for the organization, systematization and (re) orientation of the process of construction of the knowledge of the individuals involved. It was decided to problematize and present this experience from the perspective of authors who discuss popular education (FREIRE, 1981, 1997, 2011a, 2011b), education of youth and adults in prisons (IRELAND, 2011; MAEYER, 2011; MUÑOZ, 2011) and university extension (FREIRE, 1983; MELO NETO, 2012). The methodological approach is based on a qualitative approach, with a descriptive case study. The participatory observation and documentary analysis (report of the meetings) were adopted as a methodological procedure and have, as research subjects, teachers and penitentiary agents of youth and adults education participating in the aforementioned extension project, as well as the teachers/ researchers of the same project. In this extensionist action, they were considered the interests, the educational and human needs of the actors who make daily life in prison.
\end{abstract}

\section{Keywords}

Youth and Adults Education in Prisons. Dialogue. University Extension.

\footnotetext{
* PhD student in Education, Federal University of Paraíba, State of Paraíba, Brazil; member of the research group Observatório da Educação Popular. E-mail: ligia.isidio@gmail.com

** Master of Popular Education Federal University of Paraíba, State of Paraíba, Brazil. E-mail: jucilenedias@ hotmail.com.

*** PhD in Social Sciences, Pontifical Catholic University of São Paulo, State of São Paulo, Brazil; associate professor IV at the Universidade Federal University of Paraíba, State of Paraíba, Brazil; member of the research group Observatório da Educação Popular. E-mail: severinobsilva@uol.com.br.
} 


\section{Introdução}

As mudanças sociais abriram espaço para o entendimento da necessidade de alargamento da concepção e da orientação da Educação de Jovens e Adultos (EJA). Novas ênfases vão além dos limites da escolarização. Dessa maneira, sugerem considerar os sujeitos, as suas demandas sociais e suas historicidades, o que envolve, necessariamente, a diversificação de projetos de formação de educadores, a partir da formação ético-político-pedagógica.

Tal formação, a partir do desmonte da educação de adultos, orientada pela educação popular na década de 1960 (ditadura civilmilitar), sofre consequências notáveis em sua concepção, metodologia e princípiosideológicos, década em que, segundo Scocuglia (2015), foi o período de maior efervescência e processos multiplicadores de ações visando alfabetização e politização dos educandos e educandas.

Ao longo de sua história, a visão determinante da EJA foi alvo dos grupos hegemônicos que estavam no poder. Manipulada, servia como "curral eleitoral" e instrumento para a formação de mão de obra barata para favorecer o processo de industrialização.

Por certo, o golpe que começou em 1964 desarticulou e impediu a continuidade de exercícios emancipatórios instaurados através dos Círculos de Cultura iniciados no Recife que tomaram conta do país, sobretudo do nordeste brasileiro, atendose a uma educação com ênfase na instrução elementar, sem vestígios que possibilitassem uma conscientização social e política. O processo de redemocratização da educação a partir da Constituição Federal de 1988 reconhece a educação como um direito subjetivo dos jovens e adultos, dando ênfase à obrigatoriedade para todos/as aqueles/elas que não tiveram acesso à educação em tempo hábil. A Lei de Diretrizes e Bases da Educação Nacional (LDBEN), lei no 9.394/1996, no artigo 37 , reitera o que promulga a Constituição e reconhece a EJA como modalidade de ensino da educação básica, assegurando "oportunidades educacionais apropriadas, consideradas as características do alunado, seus interesses, condições de vida e de trabalho, mediante cursos e exames" (BRASIL, 1996).

Por sua vez, a V Conferência Internacional de Educação de Adultos (CONFINTEA) ${ }^{4}$, realizada em Hamburgo, na Alemanha, em 1997, corrobora a ideia voltada para a ampliação da EJA, entendida como uma "educação que se dá ao longo da vida" (DINIZ, 2010, p. 248); reafirma a multiplicidade de contextos em que acontece a educação e a indissociabilidade dessa atividade educativa que engloba as diversas dimensões da vida dos sujeitos e, nesse sentido, a prisão, por exemplo, apresenta-se como um desses espaços onde ela pode ocorrer.

Nessa Conferência, a concepção de educação de adultos foi alargada de maneira a enfatizar as necessidades dos "novos" sujeitos da EJA. Os grupos minoritários que, até então, não tinham a sua singularidade atendida, passam a ter prioridade, a partir de uma agenda com foco na interculturalidade e transversalidade das ações educativas. Os aspectos relacionados à questão de gênero, aos povos do campo, ao multiculturalismo, à cultura, assim como à categoria juvenil, entram na pauta como especificidades a serem atendidas.

A interculturalidade abre caminhos alternativos para o reconhecimento da diversidade enquanto potencialidade nos processos educativos. Trata-se de articular espaços que favoreçam o diálogo das diversidades de sujeitos e culturas. No entanto,

4. De acordo com Diniz (2010, p. 248), "a origem do conceito de aprendizagem ao longo da vida se remonta aos anos setenta, nos relatórios da UNESCO". Nesse sentido, a perspectiva de educação ao longo da vida passa a ser pauta nas CONFINTEAs 
demanda uma "arquitetura pedagógica" que possibilite a criação de tempos e espaços específicos para a mediação de conhecimentos e que extrapole a dimensão educativa formal (escolar) e, ainda, favoreça "de maneira colaborativa e interdisciplinar a construção do projeto de vida com o aprisionado" (ONOFRE; JULIÃO, 2013, p. 65).

Considerando a necessidade de aprimoramento de práticas educativasemancipatórias dentro dos espaços prisionais, este artigo apresenta algumas reflexões acerca das perspectivas metodológicas do "Projeto de Extensão Universitária Educação de Jovens e Adultos no contexto prisional". Trata-se de um projeto vinculado à Universidade Federal da Paraíba (UFPB) que esteve em vigor durante o ano de 2015 e atendeu cerca de oitenta cursistas/educadores $^{5}$ (professores e agentes penitenciários) da rede estadual de ensino da Paraíba quetrabalham comaEJA prioritariamente situados nas unidades prisionais.

O curso foi dividido em seis módulos, a saber: Ambientação EAD/Introdução à pesquisa; Fundamentos Teóricos da Privação de Liberdade; Histórias da Educação de Jovens e Adultos; A Educação de Jovens e Adultos Privados de Liberdade; A prática educativa nas prisões na interface com a Educação de Jovens e Adultos; e Seminário de Pesquisa. Os encontros formativos aconteciam quinzenalmente.

\section{Fundamentação teórica}

As discussões e estudos no âmbito da educação em prisões têm sido defendidos e referendados por estudiosos da área como uma instituição educativa e possibilidade emancipadora (IRELAND, 2011). Fator que implica conceber que a educação no espaço prisional é um processo "permanente de todos aqueles que têm alguma ligação com a prisão" (GONÇALVES et al., 2010, p. 35).

Embora se perceba que houve avanços importantes, ainda existe uma lacuna no que tange ao ensino-aprendizagem eficiente. De acordo com dados estatísticos, apenas 20\% das pessoas privadas de liberdade frequentam alguma atividade educativa. Salienta-se que, dentro de uma realidade em que $70 \%$ das pessoas não concluiu sequer o ensino fundamental, a quantidade de reclusos que frequentam atividades educativas é baixa. Esse indicativo pode ser fruto da invisibilidade do ambiente prisional como um espaço de aprendizagem e políticas públicas educacionais específicas para esse fim (ONOFRE; JULIÃO, 2013). De acordo com Aguiar (2009), nos últimos anos o Brasil encontra-se entre os cinco países com maior população prisional do mundo, apontando uma estimativa de cerca de 500 mil presos, ficando subordinado apenas a países como Estados Unidos $(2,2$ milhões), China (1,5 milhão) e Rússia (870 mil). No caso do Brasil, a situação vem se agravando ainda mais nos últimos anos. Com base no Levantamento Nacional de Informações Penitenciárias (Infopen), realizado pelo Ministério de Segurança Pública, por meio do Departamento Penitenciário Nacional (Depen), foi possível identificar que a população carcerária brasileira chegou a 726.712 de pessoas privadas de liberdade em junho de 2016. Tal levantamento foi feito junto a 1.422 unidades prisionais no Brasil. Os dados são referentes a todo o ano de 2015 e o primeiro semestre de 2016 e indicam que,

em junho de 2016, a população prisional brasileira ultrapassou, pela primeira vez na história, a marca de 700 mil pessoas privadas

5. Adotamos a terminologia "educadores" para identificar professores e agentes penitenciários, haja vista que a educação nas prisões deve contar com a participação de todos os envolvidos no contexto para se efetivar. Sobre isso, Mayer (2011, p. 54) nos diz: "se todos não são professores, todos podem ser educadores: agentes penitenciários, pessoal administrativo". 
de liberdade, o que representa um aumento da ordem de $707 \%$ em relação ao total registrado no início da década de 90. (BRASIL, 2017, p. 9).

Vê-se um crescimento demasiado com relação ao número de presos nas últimas décadas no Brasil. Nesse contexto, o Estado de São Paulo é destaque, por concentrar maior número de presos, totalizando 240.061, que equivale a $33,1 \%$ de toda população prisional do Brasil. Já o Estado de Roraima, contava com 2.339 pessoas presas, representando o estado com menor população prisional, enquanto que a população prisional do Estado da Paraíba era de 11.377 pessoas privadas de liberdade.

Outro dado relevante corresponde ao quantitativo de $70 \%$ dessa população carcerária brasileira não possuir o ensino fundamental, muitos deles não são alfabetizados. Essa realidade apresenta-se como uma problemática que requer a ampliação do discurso político a esse respeito, assim como do debate acadêmico, de modo que novos estudos possam melhor encaminhar mudanças relacionadas à questão e subsidiar políticas públicas para a área (JULIÃO; ONOFRE, 2013).

Nesse sentido, imbuído dessas prerrogativas, entendimento da complexidade do contexto prisional e necessidade de formação específica dos educadores que atuam nesse espaço de educação, o projeto de extensão mencionado articula ensino, pesquisa e extensão, a partir dos conhecimentos sobre a EJA em unidades prisionais no Estado da Paraíba. Entende-se a ação educativa como um processo dinâmico que se retroalimenta por meio da indagação, da ação problematizadora, da curiosidade epistemológica e da produção do conhecimento.

\section{Metodologia}

A base teórico-metodológica do projeto de extensão fundamentou-se no processo dialógico entre ensinar e aprender, que valoriza os conhecimentos construídos ao longo das experiências dos sujeitos, que favorece a programação, redimensionamento e/ou ressignificação dos fazeres docentes, de modo que a aquisição do conhecimento contínuo extrapole os encontros de formação, atingindo os espaços de atuação dos educadores.

Constituem-se possibilidades à partilha de saberes e principalmente para compreensão da realidade a partir da ótica do "outro". Uma atividade que não envolve uma relação de imposição, mas de abertura para entendêlo (o "outro"), sem, contudo, curvar-se, e sim elaborar um conhecimento de confrontamento (político) ou de confirmação do aprendido.

É uma ação com os educandos do contexto prisional a partir da realidade que os orienta. Nesse cenário, a ação do educador não é de estender nem de depositar conhecimento, mas, dialogicamente, aprender e ensinar junto. Não se trata de uma tarefa fácil, haja vista que envolve contradições, autocrítica e reelaboração de formas de ação consciente (do educador e do educando), mas extremamente necessária.

Nosso interesse é refletir sobre o processo metodológico utilizado nessa atividade de educação de educadores e o processo de elaboração e (re)orientação das práticas educativas dos cursistas e da equipe pedagógica que participaram do curso. Para tanto, o trabalho encontra-se ancorado nas ideias freireanas de educação como prática favorável para a emancipação, com o objetivo de analisar como se deu o processo de construção do conhecimento dos cursistas/ educadores e da equipe pedagógica, e os possíveis desdobramentos dos conhecimentos nos espaços de atuação desses profissionais, observados a partir dos relatos de experiências de certos educadores durante os módulos do curso.

Com isso, ancorados/as na perspectiva dialógica defendida por Freire (2011b), 
vislumbra-se criar possibilidades de desenvolvimento de uma prática educativa com vistas à mediação de conhecimentos importantes para a formação integral dos educandos apenados, diante dos desafios que se apresentam nos espaços de privação de liberdade, por meio da comunicação de saberes entre a universidade e os educadores que atuam com esses educandos.

Optou-se por problematizar a temática com autores que discutem educação popular (FREIRE, 1997, 1981, 2011a, 2011b), educação de jovens e adultos em prisões (IRELAND, 2011; MAEYER, 2011; MUÑOZ, 2011), educação emancipatória (SANTOS, 2007; FREIRE, 2011a).

$\mathrm{O}$ percurso metodológico baseia-se em uma abordagem qualitativa, com estudo de caso de cunho descritivo. Adotaramse como procedimentos metodológicos a observação participante e a análise documental (relatório dos encontros), e têm-se como sujeitos da pesquisa professores e agentes penitenciários da EJA participantes do "Projeto de Extensão Universitária em Educação de Jovens e Adultos no contexto prisional", da Universidade Federal da Paraíba, assim como os professores/pesquisadores do referido projeto.

\section{O diálogo como mecanismo fundante para o desenvolvimento da prática educativa numa perspectiva emancipatória}

A partir do entendimento do diálogo como mecanismo favorável para a superação da relação pedagógica verticalizada e "bancária", o qual se apresenta como uma estratégia de respeito aos saberes culturais, que são expressões de uma prática social, a dimensão metodológica do projeto foi desenvolvendo-se a partir do contexto real. Nesse cenário, a organização pedagógica contrapunha-se à ideia de estender conhecimento, mas, dialogicamente, aprender e ensinar junto, que, segundo Paulo Freire:
Nasce de uma matriz crítica e gera criticidade (Jaspers). Nutre-se do amor, da humildade, da esperança, da fé, da confiança. Por isso, só o diálogo comunica. E quando os dois polos do diálogo se ligam assim, com amor, com esperança, com fé um no outro, se fazem críticos na busca de algo. Instala-se, então, uma relação de simpatia entre ambos. Só aí há comunicação. (FREIRE, 2006, p. 107).

A perspectiva dialógica fundamentou as atividades desenvolvidas no curso. O trabalho dos professores/pesquisadores que ministravam os módulos, assim como os da equipe pedagógica, buscou desenvolver uma prática investigativa a partir da problematização que instigava os cursistas/educadores a pensarem criticamente, de modo a colocarem em pauta suas necessidades de formação, inquietações, anseios e perspectivas de aprendizagem diante do contexto de sua prática, favorecendo uma nova maneira de pensar e fazer educação que resultasse em uma leitura crítica do contexto prisional. É uma metodologia que se ancorou na investigação dos fenômenos que implicam no conhecimento das particularidades, explicitação dos fatos a partir da ação realizada no dia a dia das unidades prisonais. Trata-se de uma prática reflexiva pautada no diálogo, na inquietação e na pergunta, com possibilidade de respostas não imediatas e emergenciais (SCOCUGLIA, 2015), mas enquanto um processo que exige "curiosidade epistemológica", envolvimento sistemático fundamentado na "esperança" e na "utopia".

Nesse processo, o conhecimento é compreendido como um fenômeno comunicativo entre "sujeito-mundo-sujeito", que favorece a compreensão e (re)elaboração da concepção de mundo. Nesse cenário, a intercomunicação é apontada como elemento que constitui o homem enquanto sujeito social.

$$
\text { Cientes da necessidade do }
$$
desenvolvimento de uma prática educativa que 
suscitasse a troca de saberes que extrapolasse as experiências pessoais de aquisição de conhecimento, e que fizesse parte do trabalho diário do saber e fazer educativo no contexto prisional nos levou a questionar quanto às perspectivas metodológicas necessárias que dessem conta desse fim.

Percebeu-se ser coerente considerar a perspectiva freireana de "descodificação". Dessa forma, os professores/pesquisadores atentavam-se em não apenas ouvir os cursistas, mas também em desafiá-los, problematizando, de um lado, a situação existencial codificada e, de outro, as próprias respostas que iam dando a esses cursistas no decorrer do diálogo. Nesse sentido, os participantes ao longo dos encontros iam expondo "pela força catártica da metodologia, uma série de sentimentos, de opiniões, de si, do mundo e dos outros, que possivelmente não estrotejariam em circunstâncias diferentes" (FREIRE, 2011b, p. 157).

A equipe pedagógica, junto com os professores/pesquisadores, decidiu adotar uma metodologia que não estivesse distante da realidade dos educadores, ou seja, por meio da qual apresentassem para os cursistas questões básicas, fundamentais para o exercício de uma ação, que valorizassem os sujeitos, seus saberes, sua história de vida e suas perspectivas, e que fossem a mola propulsora da instigação e (des)construção dos possíveis estereótipos que eles mesmos, cursistas/ educadores, possuíssem acerca da prisão, dos educandos e da educação naquele espaço.

Essa perspectiva metodológica foi cunhada por Paulo Freire e sua equipe de coordenadores desde a década de 1960, a qual era denominada como Círculos de Cultura, que possuíam, como elemento fundante metodológico, o diálogo, e a premissa política como princípio essencial da ação pedagógica (SCOCUGLIA, 2015).

$\mathrm{Na}$ perspectiva freireana, a linguagem do educando deve ser um ponto-chave para a organização do ensino e aprendizagem. Para Freire (1997), faz-se necessário que o educador conheça a linguagem dos seus educandos e seja sensível à sua cultura, suas necessidades, sem, contudo, distanciar-se da sua cultura e responsabilidade ético-político-pedagógica, mas dialogicamentefavoreceraintercomunicaçãodos conhecimentos com intuito de instrumentalizar os envolvidos frente à luta contra a dominação.

No trabalho realizado na perspectiva dialógica, a linguagem ocupa centralidade, assim sendo, "no contexto de uma prática social livre e crítica. Liberdade e crítica que não podem se limitar às relações internas do grupo, mas que necessariamente se apresentam na tomada de consciência que ele realiza de sua situação social" (FREIRE, 2006, p. 10). Orientadas/os por essas prerrogativas, os professores/pesquisadores iniciaram as atividades dialogando com os cursistas/ educadores acerca das suas perspectivas sobre o curso, as suas necessidades pedagógicas dentro das unidades, com o intuito de conhecer a linguagem dos sujeitos/educadores que atuam na EJA em prisões, tanto professores, quanto agentes penitenciários.

A multiplicidade de áreas de formação dos cursistas/educadores é extremamente diversa e, por isso, rica. Variava, desde a licenciatura em Ciências Biológicas ao bacharelado em Ciências da Computação e Direito. Na medida em que se percebia o quão plurais são os sujeitos que atuam nas unidades prisionais e as diversas possibilidades atreladas a esses sujeitos dentro das salas de aula da EJA e na unidade prisional como um todo, os desafios se tornavam maiores, haja vista que muitos não possuíam conhecimento prático validado

6. Na perspectiva freireana, a "descodificação" é um ato de construção do conhecimento a partir da açãoreflexão-ação, incluindo as situações já vividas. Portanto, "busca promover a percepção da percepção anterior e o conhecimento do conhecimento anterior, a descodificação desta forma, promove o surgimento de nova percepção e o desenvolvimento de novo conhecimento" (FREIRE, 2011b, p. 153). 
quanto à dinâmica entre ensinar e aprender.

As rodas de conversas organizadas durante o curso revelaram que, embora certos cursistas/ educadores não possuíssem experiência no âmbito da prática educacional escolarizada, por causa da sua formação acadêmica e atuação profissional, sabiam da importância da educação em prisões e do seu poder de revelar e desnudar o mundo; ao mesmo tempo, tinham os que ainda possuíam uma visão limitada acerca do papel da educação nos ambientes prisionais e da importância do seu fazer nesse espaço.

Nesse sentido, as ações dos professores/ pesquisadores orientavam-se com o intuito de favorecerasolidariedadeeducativa ecolaborativa entre os agentes e os professores, até porque, dentro das salas de aula do ambiente prisional, sem essa parceria, o trabalho docente não se efetiva. Mayer (2011) advoga pela necessidade da parceria de todos os atores nas atividades realizadas no espaço prisional. Para ele, as ações desenvolvidas nesses espaços podem ser favoráveis para "trocas, aprendizagem positiva, conhecimento e reconhecimento dos outros, de implicação valorizada" (MAYER, 2011, p. 54).

$\mathrm{Na}$ perspectiva teórica de Boaventura de Sousa Santos (2007), a solidariedade é entendida como uma dimensão ética e política que impulsiona a construção da democracia e da justiça social. Trata-se de um elemento emancipatório em busca da superação da objetificação, pautado em uma lógica éticopolítico horizontal entre sujeitos sociais favoráveis à construção social coletiva. Nesse sentido, a solidariedade está relacionada à reinvenção da emancipação social e motivada pela esperança de que um outro mundo é possível. Para o autor, os mecanismos de opressão e de dominação são múltiplos e é necessário lutar de maneira articulada com objetivo de superar esse quadro. A solidariedade amplia o seu significado conceitual, assumindo características específicas de resistências e lutas frente à crise civilizatória, de opressão, negação e desvalorização do outro (SANTOS, 2007).

A responsabilidade social de cada profissional e a necessidade de cada um assumir seus fazeres sem transferências de responsabilidades foi temática de discussão. Nesse bojo, o entendimento da prisão como uma punição para os privados de liberdade que não se extrapola ao direito à educação, a saúde e a políticas sociais de modo em geral era a mola propulsora das atividades (IRELAND, 2011).

O fazer educativo nas prisões possui o desafio de repensar a prisão como um espaço de aprendizagem, reflexão e tomada de consciência crítica envolvendo todos os atores e profissionais inseridos nesse contexto. Tratase de um processo que provoca mudanças na prática cotidiana dos que ali vivem ou trabalham (agentes penitenciários e professores).

É relevante atentar-se à complexidade do fazer educativo nas prisões, tendo em vista os limites impostos pelo contexto em si, mas isso não pode resultar na redução das práticas educativas à mera escolarização. Como qualquer processo educativo, há que se buscar entender os interesses e as necessidades de aprendizagem da população carcerária e quais os limites que a situação impõe sobre esse processo (IRELAND, 2011).

De acordo com Esteban (2009), a presença do conflito e da complexidade nas práticas escolares não se reduz a soluções simples e simplificadoras; o desafio é ir além, criar novos sentidos para a escola, diferentes dinâmicas socioculturais de produção, validação e sistematização dos conhecimentos. A partir do conceito de "caos" e "crise" ${ }^{\text {"7 }}$ de Boaventura, a

7. Para melhor entendimento acerca do conceito cunhado por Boaventura de Sousa Santos, sugerimos a leitura do livro intitulado: SANTOS, B. de Sousa. Para uma pedagogia do conflito. In: FREITAS, A. L. S.; MORAES, S. C. (Org.). Contra o desperdício da experiência: a pedagogia do conflito revisitada. Porto Alegre: Redes Editora, 2009. p. 15-40. 
autora salienta que o caos e a crise são questões interessantes a se refletir, haja vista que não simbolizam um mero movimento de desordem, pois suscitam a necessidade de novas práticas no ato educativo, possibilidades que impulsionam a transformação e (re)organização dos processos de ensinar e aprender, revitalizando os contextos sociais, recuperando o caos, a crise, o conflito e as diferenças como partes do processo educativo.

O delito como parâmetro para o desenvolvimento das ações educativas foi substituído por uma educação humanística que, para Freire (2006), refere-se ao entendimento dos educandos como seres históricos capazes de ultrapassar os determinismos, de ir além, de traçar um caminho, de interpretar, de analisar, de interagir com a cultura e produzir conhecimento.

Os desafios foram se apresentando ao longo do curso e o diálogo foi especialmente importante para ultrapassá-los. Para certos cursistas/educadores, era visto como desnecessário, ou "democrático demais", posto que eles não estavam acostumados a trabalhar com a autoavaliação durante as etapas. A equipe passou a apresentar a importância do diálogo e mostrar o quão enriquecedoras e democráticas ficam as experiências, ao mesmo tempo em que favorecem a formação de sujeitos autônomos e atuantes diante das suas realidades. Tratase de uma ação pedagógica comprometida com o desenvolvimento de educação popular que possibilite compreender a realidade $\mathrm{e}$ suas complexidades, pautada na dimensão politica-pedagógica da decisão, da denúncia e do anúncio apresentando novos mecanismos de intervenção na realidade social (PALUDO, 2006).

O desenvolvimento de competências que visem à participação social e cidadã dos educandos é uma dimensão de conhecimento importante para o jovem e o adulto, favorece a oportunidade de fortalecer e experienciar o trabalho coletivo e a cooperação com o intuito de conhecer a realidade e intervir diante dos problemas. Para Pontual (2006), a participação cidadã é uma competência, é um motor para a democracia e para as conquistas.

Os educadores eram desafiados cotidianamente a promover uma prática educativa democrática que valoriza procedimentos e embasa suas ações dentro das prisões em uma perspectiva crítica e fundamentada nos "direitos ao conhecimento" demandados por Freire (2000): de conhecerem melhor o que já conhecem a partir da sua prática e de conhecerem o que ainda não conhecem, portanto, de participar da produção do novo conhecimento.

Essas perspectivas coadunam com os postulados de Mayer (2011, p. 48). O autor, ao refletir acerca do papel da educação nos âmbitos prisionais, salienta que ela "deve ajudar o detento a formular sua demanda de educação e a satisfazê-la mesmo que todos não percebam de imediato as potencialidades do método educativo". Reconhecer esses direitos dentro das salas de aula das unidades prisionais trata-se de almejar novos rumos da EJA em particular e da educação como um todo; é repensar as práticas educativas a partir dos interesses, da cultura, do conhecimento dos sujeitos, e reconhecer que a centralidade da prática educativa deve ser o educando e sua história.

Para Freire (2011b), trata-se de um projeto educativo emancipador que nega a educação como regulação, uma pedagogia que se dá no processo dialético da práxis humana, ação-reflexão-ação, permitindo aos sujeitos a consciência de si e da real situação que se experimenta.

Tais fundamentos contribuem para a tomada de consciência e o entendimento do lugar que ocupa no mundo, possibilidade de reescrita da sua história e emancipação. Os sujeitos em situação de cárcere possuem uma restrição à liberdade, o que suscita o afastamento da sociedade, privando-os de relações com 
o mundo externo. A prisão é um espaço criado exclusivamente para distanciar, punir, apresentando-se como um ambiente conflituoso e complexo, mas, além disso, é um espaço de ressocialização, de reflexão, de perspectivas de mudanças, que visam ressignificar o passado em direção a um projeto de vida futura, uma vida diferente a ser tomada quando recuperada a liberdade (IRELAND, 2011).

Muñoz (2011) elenca uma série de obstáculos que compromete a educação nos estabelecimentos penais de maneira em geral; dentre esses entraves, cita os institucionais e situacionais, que se referem a jogos de poder, precariedade do espaço físico, insalubridade, escassez de recursos pedagógicos, falta de formação específica, indisposição dos educandos justificada pela trajetória educacional de fracasso escolar, entre outros. Esse contexto de complexidade educacional a que os educadores das unidades prisionais estão sujeitos corrobora a desesperança e baixa autoestima do profissional, pois ainda não é uma prioridade no conjunto do sistema prisional.

A desesperança é fruto de um processo histórico de impossibilidades, discursos fatalistas e deterministas (FREIRE, 2011b). Não diferente e talvez um pouco mais aguçado, os educadores das unidades prisionais que fazem parte do curso de extensão apresentavam, por vezes, esses sentimentos, por já estarem, de certa maneira, impregnados pela dinâmica conflituosa do dia a dia nas unidades em que atuam.

Ao longo dos encontros, a complexidade do trabalho nas prisões era retratada pelos educadores, realidades adversas e, por muitas vezes, desumanas. Contudo, junto a isso, ouviram-se relatos esperançosos, de persistência e desejo de uma formação específica que contribuísse para o entendimento daquele contexto. Diante disso, perguntou-se de que forma poder-se-ia contribuir para a construção de caminhos favoráveis a efetivação de uma ação educativa significativa tanto para os apenados, quanto para os educadores.

A persistência, a participação assídua, relatos e inquietações, frente ao contexto de sua prática, pronunciados por certos educadores, ao longo dos encontros, foram elementos indispensáveis para a efetivação da ação formativa. Por meio dos relatos, por exemplo, os professores/pesquisadores iam entendendo a realidade prática e (re)orientando a dinâmica nos encontros. Uma lógica de construção coletiva, em que juntos iam compreendendo e buscando alternativas para desenvolver ações coerentes com as necessidades do contexto em voga, ou seja, a partir do desenrolar do projeto de extensão, novos conhecimentos desdobravam-se e retroalimentavam o projeto.

Acreditar em novas possibilidades dentro de um contexto complexo seria um mecanismo de superação dos determinismos, uma alternativa que vai além das tensões e conflitos educacionais. Nesse sentido, o sonho é compreendido como uma possibilidade, ou seja, não existe mudança sem sonho, assim como não existe sonho sem esperança (FREIRE, 2011a).

Faz-se importante reconhecer as limitações, o conflito e a complexidade presentes na prisão, assim como em outros espaços educativos. Mas o fazer do educador, em uma perspectiva diferenciada, mostra-se uma alternativa desafiadora e eficaz quando pautado em uma "pedagogia da esperança" que não enxerga a realidade como estática, mas dinâmica, que se movimenta o tempo todo, uma lógica de rebeldia que ultrapassa o dito, que vai além, que busca um fazer educativo que suscite novas práticas daqueles que participam do processo.

Para Freire (1997), a decisão política, enquanto motor da atividade do mediador/ educador será o divisor entre uma prática educativa fatalista, determinista, e uma prática educativa com vistas à emancipação. A ação ético-política no ato de educar é alvo de análise de Freire, em suas escritas e reflexões, nas quais o autor trabalha essa questão sinalizando que, 
quando o educador assume a dimensão política nas suas ações, está fazendo uma decisão ética de respeito aos educandos. Esse posicionamento ético ultrapassa as questões epistemológicas que se referem apenas aos compromissos com a qualidade dos conhecimentos sistematizados, competências e habilidades a serem mediadas; para além disso, diz respeito à consideração humana dos educandos.

Nessa simbiose, o desafio do projeto de extensão voltou-se ao ato de educar em uma perspectiva de ação ético-política com o objetivo de valorizar a realidade situacional dos educadores, assim como dos jovens e adultos em situação de privação de liberdade. A ideia não é pensar sobre uma pedagogia conteudista, mas uma possibilidade educativa em que as condições humanas e sociais sejam substanciais e pontos de partida para o desenvolvimento da prática extensionista, haja vista que a extensão é comunicação entre saberes com vistas à cidadania, tomada de consciência e entendimento da realidade daqueles que participam e que isso se faz por meio do conhecimento compartilhado entre aqueles que fazem parte desse processo. Essa perspectiva dialoga intimamente com a expectativa da extensão universitária alicerçada filosoficamente e metodologicamente pela educação popular, a qual preza pela condução da conquista da cidadania, conscientização e atuação transformadora.

Esse tipo de ação realizada a partir da perspectiva popular pela universidade, de acordo com Melo Neto (2012), trata-se de uma "extensão popular". Para o estudioso, é uma atividade dialógica entre a universidade e a comunidade, a partir da realidade objetiva vivenciada. Uma ação compartilhada que entende que todos os sujeitos envolvidos têm muito a contribuir, um trabalho orientado pela educação necessariamente problematizadora, um "trabalho social útil", ou seja, "é um trabalho social, por não ser exercidos como uma tarefa individual; é útil, levando em conta que esse trabalho pretende expressar algum interesse e atender a determinadas necessidades humanas" (MELO NETO, 2012 p. 58).

Nesse sentido, a ação extensionista desse curso considerou os interesses, as necessidades educacionais e humanas dos atores que fazem o cotidiano na prisão. A partir do diálogo, visou oferecer subsídios favoráveis à prática educativa que considera o outro e que, além disso, instiga a reflexão de sua condição histórica e social, assim como a capacidade e possibilidade de ir além, de superar e desnudar novos horizontes.

Como já mencionada, é uma atividade desafiadora, mas que tem o potencial de forjar uma nova consciência dos sujeitos com o intuito de atingir um melhor nível de criticidade. É a partir do desenvolvimento de propostas humanísticas de educação que prezam pela emancipação dos sujeitos, como meio de transformação de sua realidade histórica e social, que novos caminhos vão se constituindo.

Essa experiência de extensão popular é um indício de que a tendência freireana de combate à alienação é possível quando, a partir das atividades extensionistas realizadas pela universidade, trataria da indissociabilidade entre o ensino e a pesquisa e, ao mesmo tempo, desenvolveria ações com vistas à mediação da construção da "consciência de si". Uma atividade que produz conhecimento e consciência com vistas à transformação.

A experiência no âmbito do projeto de extensão apresentou-se como possibilidade de efetivação do papel social da universidade através de desdobramentos no saber/fazer universitário da equipe pedagógica e de extensionistas envolvida - bolsistas, tutores, professores/pesquisadores e coordenadores - no sentido de contribuir substancialmente no processo de reinventar conhecimentos e práticas a partir dos desafios junto aos cursistas. Desafios que começam pela especificidade do campo da experiência de um 
lado e, por outro, da não vivência da equipe pedagógica com a EJA no contexto prisional. Foi extremamente provocante e, a cada passo, grandes descobertas, como: primeiro discutir EJA com professores e agentes penitenciários que, até então, não trabalhavam em equipe; depois, a felicidade dos apenados ao receber a universidade no presídio, de modo que os professores/pesquisadores foram recebidos com muita cultura (dança e música); poder relacionar o contexto com as leituras acadêmicas e dialogar com os educadores (professores/ agentes); e perceber como a experiência contribuiu para despertar a curiosidade dos educadores, no sentido de humanização das ações no presídio e de formação para cidadania.

Foram vivenciados momentos que se constituíram em espaços de aprendizagens, os quais permitiram coletivamente a construção de um novo modo de compreender as práticas social, cultural, profissional e científica, e, a partir daí, apresentou-se como necessário caminhar do lado oposto da instrumentalização ou assistencialismo, de modo a construir alternativas por meio da problematização e da (re)elaboração das concepções e práticas político-educativas comprometidas com o "quefazer" contínuo com vistas à emancipação. Nesse caso, a escuta e as visitas ao presídio tornaram-se fundamentais para o curso, as reflexões e as ações. Nesse sentido, a escuta, a comunicação e o diálogo configuraram-se em artifícios indispensáveis ao desenvolvimento das atividades no contexto de privação de liberdade. A partir desse entendimento, a equipe pedagógica do projeto de extensão foi retroalimentando as práticas, de acordo com as demandas e as necessidades dos educadores.

\section{Considerações (in)conclusivas...}

Um dos objetivos do projeto de extensão foi criar possibilidades educativas por meio da horizontalidade das decisões e do diálogo, com intuito de favorecer condições para que o fazer educativo no contexto prisional acontecesse a partir da cooperação entre agentes penitenciários e professores, haja vista a complexidade e importância da educação nesse lócus. Essas experiências fizeram com que seus participantes compreendessem que é possível desenvolver ações formativas por meio da extensão universitária, partindo do pressuposto de que os sujeitos que fazem parte do processo são agentes construtores de conhecimentos e, nesse construto, o educador é o intermediário que deve disponibilizar condições para que eles saiam da sua posição inicial de aprendizagem e caminhem em direção ao novo conhecimento, de modo a (re)orientar sua concepção de mundo, agindo neste espaço como protagonista da mudança social.

Segundo Freire (1981), a ação do mediador deve ser a de comunicar-se com o outro. No âmbito das atividades de extensão, ela deve se dar da mesma maneira. A ação de comunicar parte da compreensão de que o outro se faz necessário para que a comunicação de fato aconteça: uma pessoa não se comunica sozinha. Essa perspectiva freireana frente à extensão tenciona e problematiza as atividades realizadas pela Universidade, através da extensão universitária. De certo, faz com que se reflita acerca da sua função [da universidade], utilidade e bases ideológicas que alicerçam essas atividades.

A proposta de uma interação dialógica e participativa são princípios significativos para a formação de sujeitos conscientes. Representa o compromisso e o respeito ao ser humano em uma perspectiva ética e humanística. Trata-se da construção do conhecimento com possibilidade emancipatória que se constitui diante das tensões, contradições, relações de poder e do fazer educativo no contexto prisional; apresenta-se como indício que pode favorecer o reconhecimento da capacidade dos sujeitos em projetar um futuro a partir da "consciência 
de $\mathrm{si}^{\prime \prime}$.

Considerando sua função educativa, o projeto de extensão, dentro das possibilidades e limites para a sua realização, levou professores/pesquisadores a programarem ações com intuito de viabilizar a educação dos educadores e sua qualificação continuada, ao mesmo tempo em que se construíam novos saberes e se refundamentavam concepções, uma simbiose interativa de saberes, que, sem dúvida, conduzirá a mudanças dentro da sala de aula nos presídios, sobretudo na dinâmica das unidades penitenciárias, na maneira de se conceberem os sujeitos apenados e na forma de se orientarem as ações educativas dentro e fora da prisão, de ambos os envolvidos nesta ação. Ademais, possibilitou a construção de um olhar diferente por parte da Universidade Federal da Paraíba, educadores e equipe extensionistas a respeito do trabalho

pedagógico na EJA e da extensão em um território a que não pertencemos: a prisão.

\section{Referências}

AGUIAR, A. Educação de jovens e adultos privados de liberdade: perspectivas e desafios. Paidéa, Belo Horizonte, Ano 6, n. 7, p. 101-121, 2009. Disponível em: < http://www.fumec.br/revistas/ paideia/article/view/953>. Acesso em: 16 mar. 2018.

BRASIL. Constituição (1988). Constituição da República Federativa do Brasil. Brasília, DF: Senado Federal, 1988.

Lei de Diretrizes e Bases da Educação Nacional. Lei no 9.394, de 20 de dezembro de 1996. Estabelece as diretrizes e bases da educação nacional. Brasília, DF, 1996.

Levantamento Nacional de Informações Penitenciárias - Infopen. 2016. Disponível em: <http://depen.gov.br/DEPEN/depen/sisdepen/infopen/relatorio_2016_22-11.pdf>. Acesso em: 9 ago. 2018.

DINIZ, A. V. S. A Aprendizagem ao longo da vida e os currículos biográficos de aprendizagem de sujeitos jovens e adultos. In: DINIZ, A. V. S.; SCOCUGLIA, A. C.; PRESTES, E. T. (Org.). A aprendizagem ao longo da vida e a educação de jovens e adultos: possibilidades e contribuições ao debate. João Pessoa: Editora da UFPB, 2010. p. 247-267.

ESTEBAN, M. T. Breves notas sobre um pensamento fecundo. In: FREITAS, A. L. S.; MORAES, S. C. (Org.). Contra o desperdício da experiência: a pedagogia do conflito revisitada. Porto Alegre: Redes Editora, 2009. p. 123-142.

FREIRE, P. A importância do ato de ler: em três artigos que se completam. 39. ed. São Paulo: Cortez, 2000. 102 p.

$245 \mathrm{p}$.

Ação cultural para a liberdade e outros escritos. 5. ed. Rio de Janeiro: Paz e Terra, 1981.

Educação como prática da liberdade. Rio de Janeiro: Paz e Terra. 2006. 158 p.

Educação e política. 3. ed. São Paulo: Cortez, 1997. 144 p. 
Pedagogia da esperança: um reencontro com a pedagogia do oprimido. São Paulo/Rio de Janeiro, Paz e Terra, 2011a. 245 p.

. Pedagogia do oprimido. 50. ed. Rio de Janeiro: Paz e Terra, 2011b. 253 p.

GONÇALVES, E. et al. Educação como direito humano. In: YAMAMOTO, A. et al. (Org.). Educação em prisões. Associação Alfabetização Solidária. São Paulo: AlfaSol: Cereja, 2010. (Cereja Discute, v. 1).

IRELAND, T. D. Educação em prisões no Brasil: direito, contradições e desafios. Em aberto, Brasília, v. 24, n. 86, p. 19-39, nov. 2011. Doi: http://dx.doi.org/10.24109/2176-6673.emaberto.24i86.\%25p.

MAEYER, M. de. Ter tempo não basta para que alguém se decida a aprender. Em aberto, Brasília, v. 24, n. 86, p. 43-55, nov. 2011.

MELO NETO, J. F. de. Universidade Popular. João Pessoa,PB: Editora da UFPB, 2012. 122 p.

MUÑOZ, V. O direito à educação das pessoas privadas de liberdade. Em aberto, Brasília, v. 24, n. 86, p. 57-74, nov. 2011.

ONOFRE, E. M. C., JULIÃO, E. F. A educação na prisão como política pública: entre desafios e tarefas. Revista Educação \& Realidade, Porto Alegre, v. 38, n. 1, p. 51-69, jan./mar. 2013. Disponível em: <http://www.scielo.br/pdf/edreal/v38n1/05.pdf>. Acesso em: 16 mar. 2015.

PALUDO, C. Educação popular: dialogando com redes latino-americanas (2000-2003). In: PONTUAL, P.; IRELAND, T. D. (Org.). Educação popular na América Latina: diálogos e perspectivas. Brasília, DF: MEC: UNESCO, 2006. P. 41-65.

PONTUAL, P. Educação popular e democratização das estruturas políticas e espaços públicos. In: PONTUAL, P.; IRELAND, T. D. (Org.). Educação popular na América Latina: diálogos e perspectivas. Brasília, DF: MEC: UNESCO, 2006. p. 91-102.

SANTOS, B. de S. Renovar a teoria crítica e reinventar a emancipação social. São Paulo: Boitempo, 2007. 126 p.

. Para uma pedagogia do conflito. In: FREITAS, A. L. S.; MORAES, S. C. (Org.). Contra o desperdício da experiência: a pedagogia do conflito revisitada. Porto Alegre: Redes Editora, 2009. p. $15-40$.

SCOCuGliA, A. C. A história das ideias de Paulo Freire e a atual crise de paradigmas. 6. ed. João Pessoa: Editora da UFPB, 2015. 161 p.

A teoria só tem utilidade se melhorar a prática educativa: as propostas de Paulo Freire. Petrópolis, RJ: De Petrus et Alii; Rio de Janeiro: FAPERJ, 2013. 208 p.

Submetido em 29 de maio de 2018.

Aprovado em 27 de julho de 2018. 